\title{
SIMPÓSIO DE INTERCULTURALIDADE E A DIVERSIDADE CULTURAL INDIGENA: CONTRIBUINDO COM AS AÇOES AFIRMATIVAS
}

\author{
SYMPOSIUM ON INTERCULTURALITY AND THE \\ INDIGENOUS CULTURAL DIVERSITY: CONTRIBUTING TO \\ AFFIRMATIVE ACTIONS
}

Renata Sebastiani* Anselmo João Calzolari Neto** Isabela Custódio Talora Bozzini***

\begin{abstract}
Resumo: A necessidade de reconhecer a diversidade da comunidade estudantil e de ações para a acolhida e permanência dos estudantes indígenas na Universidade Federal de São Carlos culminou no I Simpósio de Interculturalidade, atividade de extensão realizada em maio de 2015. Os objetivos a serem alcançados com a descrição desta atividade foram compartilhar as experiências do evento, destacar a atuação dos estudantes indígenas e não indígenas durante sua organização e relatar seus desdobramentos para a comunidade universitária. Como principais resultados, destacam-se a divulgação sobre o tema escolhido, a relação da universidade com a sociedade, a integração entre os estudantes indígenas e não indígenas, o estabelecimento de um Núcleo de Estudos Indígenas e o início do Ciclo de Ações e Luta Indígena. O evento fortaleceu as atuais ações de Políticas de Ações Afirmativas da UFSCar enquanto instrumento de promoção da diversidade no ambiente universitário.
\end{abstract}

Palavras chave: Atividade de Extensão; Estudantes indígenas; Interculturalidade; Políticas de Ações Afirmativas.

\begin{abstract}
The need to recognize the diversity of the student comunity and the actions to the acceptance and permanence of indigenous students in Federal University of São Carlos (UFSCar) culminate with the First Symposium on Interculturality, an extension activity held on May 2015. Thus, this study aims to describe the results of this experience, highlighting the performance of the indigenous and non-indigenous students during the event organization, and to report its development to the university community. The main results include the dissemination of the theme, the relation between society and universiity, the integration between indigenous and non-indigenous students, the establishment of a Nucleus of Indigenous Studies, and the beginning of the Cycle of Indigenous Actions and Struggles. The event strengthened the current Affirmative Action Policies of UFSCar as an instrument to promote diversity in the university environment.
\end{abstract}

Keywords: Extension Activity; Indigenous Students; Interculturality; Affirmative Action Policies. 


\section{Introdução}

A Universidade Federal de São Carlos (UFSCar) está inserida no interior do estado de São Paulo, conta hoje com 4 campi (São Carlos, Araras, Sorocaba e Lagoa do Sino) e oferece 64 cursos, totalizando 2.897 vagas para a graduação presencial (UNIVERSIDADE FEDERAL DE SÃO CARLOS, 2017). O ingresso na UFSCar é feito pelo Exame Nacional do Ensino Médio (ENEM) e os resultados desse exame são utilizados pela UFSCar para fazer a seleção dos estudantes por meio do SISU (Sistema de Seleção Unificado).

Ainda no que se refere à seleção de estudantes, a UFSCar conta com Políticas de Ações Afirmativas, que procuram reduzir as desigualdades sociais no ingresso e na permanência de estudantes na universidade. A construção destas Ações Afirmativas, em fase de consolidação, iniciou-se em 2005 com discussões provocadas por estudantes negros da UFSCar e acolhidas pelo Conselho Universitário (SILVA; MORAIS, 2015). Segundo os autores, à medida que as discussões avançavam, foi se entendendo que "igualdade no direito à educação tem de ser garantida a todos brasileiros e brasileiras nas instituições mantidas pelo poder público" (p. 24) e "que igualdade implica necessariamente em equidade, ou seja, oferta de condições, consideradas diferenças de grupos sociais e étnico-raciais, que garantissem a efetividade do exercício do direito" (p. 25).

Nesse sentido, precisava-se encontrar um meio de reduzir as desigualdades na universidade, oportunizando meios para o ingresso, permanência $\mathrm{e}$ bons rendimentos de todos os representantes da sociedade brasileira. Analisando os dados das matrículas do corpo discente, antes da implementação das Ações Afirmativas, havia predomínio de pessoas brancas, "descendentes de europeus e oriundas de grupos sociais abastados, que haviam cursado o ensino médio em instituições privadas" (SILVA; MORAIS, 2015 , p. 22). Segundo os autores, a partir de dados da própria UFSCar, em 2006, atingiu-se 79,9\% de estudantes oriundos de escolas privadas, mesmo a universidade sendo pública, ou seja, "mantida com recursos dos impostos que todos os brasileiros pagam" (p. 22).

Assim, em dezembro de 2006, o Programa de Ações Afirmativas da UFSCar foi aprovado em decisão histórica no Conselho Universitário e sua implementação iniciou-se em 2008. Vinculados às Ações Afirmativas estão os Programas de Acolhimento e Apoio aos Estudantes e de Relações Étnico-Raciais, incluindo a reserva de vagas (SILVA; MORAIS, 2015).

O sistema de reserva de vagas prevê o ingresso de estudantes oriundos de escolas públicas na universidade, com porcentagem crescente dessas vagas ao longo dos anos em todos os cursos e, nesta porcentagem, define-se também reserva de vagas a estudantes pretos, pardos e indígenas. Desta forma, a
UFSCar passou a garantir em seu interior uma maior representatividade de outros grupos, integrantes da sociedade brasileira, que estavam excluídos do ensino superior.

Já no cenário nacional, apenas em 2012 foi aprovada a Lei $\mathrm{n}^{\circ} 12.711$, de 29 de agosto, que ficou conhecida como a lei das cotas, embora o termo adequado seja Reserva de Vagas. Ela traz, em seu artigo primeiro:

\begin{abstract}
Art. $1^{\circ}$ - As instituições federais de educação superior vinculadas ao Ministério da Educação reservarão, em cada concurso seletivo para ingresso nos cursos de graduação, por curso e turno, no mínimo $50 \%$ (cinquenta por cento) de suas vagas para estudantes que tenham cursado integralmente o ensino médio em escolas públicas (BRASIL, 2012, p. 1).
\end{abstract}

Esta lei garante o ingresso ao ensino superior de estudantes que fizeram integralmente o Ensino Médio em escolas públicas. No entanto, é um erro pensar que os estudantes não precisam se esforçar para ingressar na universidade, pois estarão concorrendo com outros colegas, que tiveram oportunidades semelhantes às suas. Segundo Oliveira e Yamaji (2015), a universidade não recebe pessoas desqualificadas por conta do processo de reserva de vagas, pois todos fazem o mesmo exame para ingresso (ENEM) e devem atingir a pontuação mínima para serem aprovados.

No que tange às questões étnico-raciais, o artigo terceiro garantia as vagas para pretos, pardos $\mathrm{e}$ indígenas (BRASIL, 2012). Por fim, uma nova redação foi realizada em 2016, incluindo-se também os estudantes com deficiência:

\begin{abstract}
Art. $3^{\circ}$ - Em cada instituição federal de ensino superior, as vagas de que trata o art. $1^{\circ}$ desta Lei serão preenchidas, por curso e turno, por autodeclarados pretos, pardos e indígenas e por pessoas com deficiência, nos termos da legislação, em proporção ao total de vagas no mínimo igual à proporção respectiva de pretos, pardos, indígenas e pessoas com deficiência na população da unidade da Federação onde está instalada a instituição, segundo o último censo da Fundação Instituto Brasileiro de Geografia e Estatística IBGE. (BRASIL, 2016, p. 1).
\end{abstract}

Desde a implementação do sistema de reserva de vagas, a UFSCar também realiza seleção diferenciada destinada especificamente para estudantes que comprovem pertencer a uma das etnias indígenas do território brasileiro, por meio de declaração de etnia e vínculo com sua comunidade de origem. A seleção dos interessados é feita anualmente por meio de processo seletivo específico, com oferta de uma vaga adicional em cada uma das opções de curso da universidade (UNIVERSIDADE FEDERAL DE SÃO CARLOS, 2017).

A partir das Ações Afirmativas, as universidades têm acolhido em seu corpo discente a diversidade cultural e étnico-racial representativa da sociedade brasileira, como destacam Silva e Morais 
(2015, p. 16):

As universidades brasileiras que já implantaram Ações Afirmativas no Ensino Superior mediante políticas de acesso e permanência têm lidado com a chegada de sujeitos sociais concretos, com saberes distintos daqueles usualmente portados por estudantes que chegavam à universidade com outras formas de construir conhecimento, o que incide sobre a forma de aprender e empregar conhecimento oriundos da academia.

A UFSCar-Araras recebe anualmente, em praticamente todos os cursos, estudantes indígenas de diferentes etnias e locais do país. Esta diversidade étnica e cultural tem propiciado discussões intensas na instituição e provocado diferentes interpretações de docentes e discentes sobre as Ações Afirmativas na universidade. A presença de estudantes de diferentes culturas e a divulgação de cada uma delas podem ser enriquecedoras para toda a comunidade. Sediar um evento intercultural na universidade permite divulgar a diversidade cultural não só dos estudantes desta universidade, mas também a diversidade cultural do país. É esperado que a universidade, por ser um local de produção e difusão do conhecimento, esteja disposta a considerar a diversidade cultural em seu meio (DAVID; MELO; MALHEIRO, 2013).

Durante praticamente todo o século $\mathrm{XX}$, as políticas educativas voltadas aos povos indígenas tiveram caráter tutorial, com vistas à apropriação da cultura da sociedade não indígena e a tendência à negação de sua cultura. Segundo Walsh (2010), desde a década de 90, há uma nova atenção na América Latina para as relações étnicas, no sentido de promover uma relação mais positiva entre distintos grupos culturais, enfrentando a discriminação e o racismo, formando cidadãos mais conscientes e capazes de trabalhar conjuntamente na busca de uma sociedade mais justa, equitativa, igualitária e plural. Mas não podemos esquecer que estas possibilidades começam quando uma sociedade é capaz de se olhar, reconhecer as injustiças e buscar caminhos para enfrentá-las.

Nesse sentido, a universidade precisa se olhar e, segundo David, Melo e Malheiro (2013), ir além da disponibilidade de vagas para estudantes indígenas para superar parte das desigualdades. Os avanços na legislação brasileira referentes à educação escolar indígena são importantes para o acesso à universidade, mas insuficientes para garantir sua efetiva implantação, por diversos motivos, tais como problemas nos sistemas educacionais locais, a diferença entre as formas de conhecimento, condições financeiras inadequadas para a permanência na universidade, formação na educação básica deficiente, identidade estereotipada do indígena, a complexidade de diálogo entre diferentes culturas, entre outros (Vilanova; Fenerich; Russo, 2011; David; Melo; Malheiro, 2013).

De acordo com Silva e Morais (2015, p. 17-18), "é função das Instituições de Ensino [...] formar cidadãos capazes de compreender e defender a diversidade da população brasileira, de dialogar uns com os outros, sem abrir mão das suas origens regionais, nacionais, étnico-raciais." De forma geral, as universidades não levam em consideração as diferenças entre as etnias e poucas são as ações institucionais que favorecem a permanência do discente indígena na universidade (David; Melo; Malheiro, 2013). A mediação do diálogo entre diferentes culturas é uma das principais dificuldades da implantação de Políticas de Ações Afirmativas, no sentido de garantir que todos sejam devidamente ouvidos e assim respeitados (SILVA; MORAIS, 2015).

Nesse sentido, sentimos a necessidade de dialogar com os estudantes indígenas da UFSCarAraras, na tentativa de compreender um pouco mais sobre a cultura destes povos que aqui estão e reconhecer as demandas dos diferentes grupos sobre a educação que esperam receber da Universidade. Assim, organizamos junto aos estudantes indígenas, estudantes não indígenas e outros segmentos da comunidade universitária, interessados na temática, o I Simpósio de Interculturalidade: "Diversidade cultural indígena", nos dias 22 e 23 de maio de 2015, na UFSCar-Araras. O objetivo deste artigo é relatar e analisar o processo de elaboração e execução de um simpósio nessa perspectiva, dialógica e intercultural.

\section{Metodologia}

Apresentamos a seguir como se deu a preparação do Simpósio de Interculturalidade na UFSCar-Araras, desde a constituição da Comissão Organizadora até a realização do evento.

A comissão contou com 23 integrantes, 4 docentes da UFSCar-Araras, 7 estudantes indígenas e 12 estudantes não indígenas. $\mathrm{O}$ evento contou também com a participação da equipe da Atividade de Extensão "Fotografia e Ciências: introdução às técnicas fotográficas e aplicações na divulgação científica", cujas fotografias obtidas foram utilizadas posteriormente pelos estudantes indígenas em diferentes eventos.

Para a organização do evento, foram realizadas cerca de 12 reuniões entre os meses de novembro de 2014 e maio de 2015. Inicialmente, a comissão organizadora foi dividida em 4 equipes: divulgação (on line e cartazes), inscrições de participantes (on line e presencial), captação de recursos (patrocínio) e infraestrutura (reserva de salas, contato com palestrantes, reserva de hotel, dentre outras). Durante o evento, esta comissão organizadora foi reagrupada em outras equipes de execução, responsáveis pela recepção dos inscritos, coffee break, decoração, fotografia e filmagem e acompanhamento da programação. Nenhuma equipe foi destinada à elaboração da programação, pois esta foi concebida e aprimorada com a participação de todos os integrantes da comissão organizadora. 
O primeiro passo para a proposição da programação do evento foi a realização de uma Roda de Conversa em dezembro de 2014, no campus de São Carlos, em que estiveram presentes cerca de 50 estudantes indígenas de diversas etnias, oriundos dos campi de São Carlos, Araras e Sorocaba. Neste momento, percebeu-se que o desejo dos estudantes era a participação de, ao menos, duas lideranças das comunidades como palestrantes, indicadas por eles. Além disso, decidiram que haveria a participação dos estudantes indígenas de todos os campi; a condução do evento pelos estudantes considerados lideranças em suas respectivas comunidades, que deveriam atuar como mediadores e palestrantes. A importância e as dificuldades para o ingresso e a permanência de estudantes indígenas na universidade foram defendidas como tema principal do evento.

O evento foi divulgado através das redes sociais mais utilizadas pelos estudantes envolvidos na comissão organizadora, assim como por meio de cartazes distribuídos nos campi e nas escolas públicas do município, via Secretaria Municipal de Educação. As inscrições para o evento foram gratuitas e realizadas on line e em caráter presencial. O jornal impresso do município também noticiou o evento (TRIBUNA DO POVO, 2015), o que nos motivou a aceitar inscrições esporádicas no dia de início do evento.

A data do evento ( 22 e 23 de maio) foi escolhida especialmente pelo fato de que estes dias faziam parte da Semana Acadêmica, presente no calendário da UFSCar-Araras, e, assim, considerada como o conjunto de dias letivos dedicados aos eventos do campus.

A partir das sugestões de lideranças indicadas na Roda de Conversa para a programação, dois nomes foram confirmados, sendo uma liderança da etnia Paratiponé e outra da etnia Xavante. Os estudantes indígenas as indicaram pelo fato de ambas falarem português fluentemente, já terem realizado curso superior e terem disponibilidade para se ausentarem de suas respectivas comunidades durante os dias do evento.

Dentre os estudantes indígenas dos diferentes campi, alguns foram escolhidos para atuarem como palestrantes e mediadores. Esta escolha foi feita pelos estudantes indígenas, devido ao fato de já serem jovens lideranças em suas respectivas comunidades e de atuarem ativamente pela vinda e permanência de novos estudantes indígenas na universidade. A programação detalhada do evento está no Quadro 1.

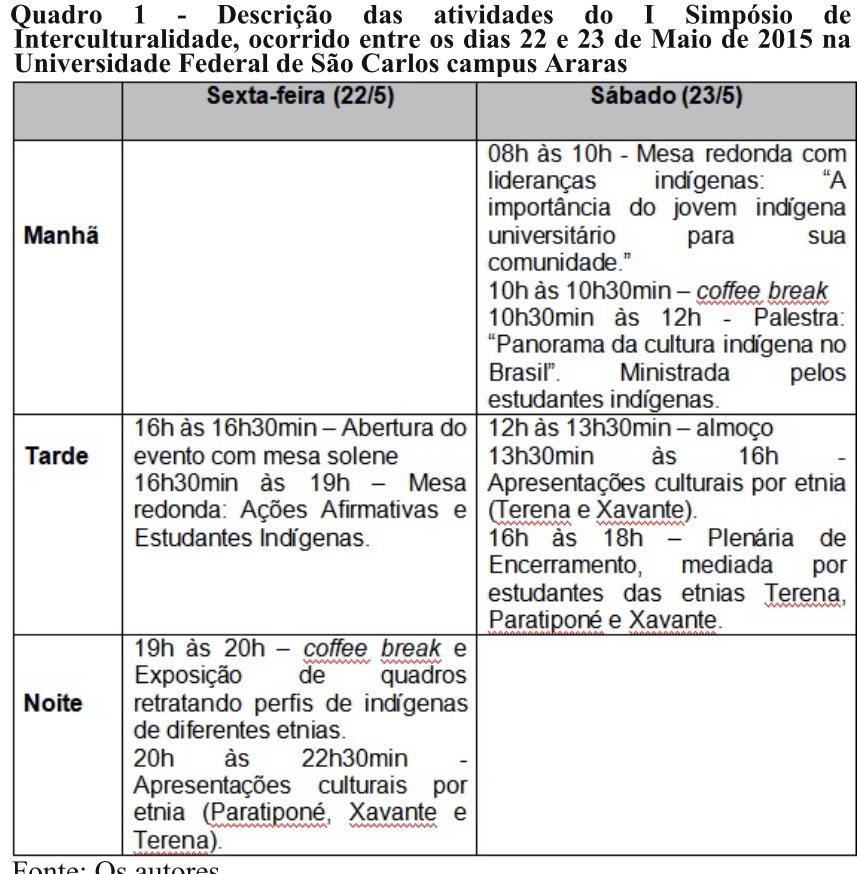

Fonte: Os autores.

O evento contou com um total de 98 participantes, dos quais 28 eram indígenas. Dentre os participantes indígenas, 17 eram estudantes do campus de São Carlos, pertencentes às etnias Dessana, Tukano, Xavante, Atikum, Kambeba, Terena, Pankararú, Wassú-cocal e Hunihui; 4 eram estudantes do campus de Sorocaba, todos pertencentes à etnia Xavante; e 7 eram estudantes do próprio campus e integrantes da comissão organizadora, pertencentes às etnias Terena, Xavante, Paratiponé e Kambeba. Quanto aos participantes não indígenas, 33 eram estudantes de graduação da UFSCar e os 37 participantes restantes, público externo da universidade.

\section{Análise dos Resultados}

As palestras e mesas redondas possibilitaram reflexões acerca da condição indígena na universidade. Ao mesmo tempo, as apresentações culturais possibilitaram a integração entre a comunidade e a universidade. Todas essas impressões apareceram na Plenária de Encerramento, como síntese. Por isso, decidimos tratar com mais detalhes este momento do evento.

A Plenária de Encerramento foi o momento em que o evento foi devidamente concluído, com as opiniões dos participantes e indicativos de ações futuras sobre a diversidade cultural indígena e o ingresso e a permanência de estudantes indígenas na universidade. $\mathrm{O}$ início desta plenária foi marcado pela apresentação da carta a ser enviada à Fundação Nacional do Índio (FUNAI) e discussão da Proposta de Emenda à Constituição 215 (BRASIL, 2000), que propunha que as demarcações de terras indígenas fossem uma responsabilidade do poder legislativo, ao invés do poder executivo. 
suas respectivas comunidades, bem como sobre a importância do ingresso e da permanência dos indígenas na universidade, foi fundamental para a valorização desses estudantes e para o reconhecimento do conservadorismo da universidade. Comentou-se que, assim como os estudantes indígenas, estudantes de outros grupos sociais, tais como os estudantes afrodescendentes, também sentem a resistência deste conservadorismo. Esta não nos parece uma atitude desejável da universidade, já que todos os grupos sociais devem ter o direito de acesso. Tais observações vão ao encontro do que destacam Silva e Morais (2015) sobre as atribuições do Programa de Ações Afirmativas, oportunidade em que a Universidade Federal de São Carlos vem

\begin{abstract}
buscando aprender a deixar de impor valores e aspirações de um grupo social como se fossem os únicos válidos para todos os cidadãos, a aprender com os movimentos sociais e grupos populares dos quais nossos estudantes são oriundos e com eles a construir uma sociedade em que todos sejam respeitados, tenham sua cultura, seu modo de ser e viver reconhecidos e valorizados. (SILVA; MORAIS, 2015, p. 25).
\end{abstract}

No nosso olhar, a universidade só tem a ganhar quando acolhe diferentes grupos sociais, pois a convivência na diversidade promove aprendizagens que ampliam a visão de mundo de todos que convivem. O multiculturalismo, segundo David, Melo e Malheiro (2013),

prega a coexistência enriquecedora de diversos pontos de vista e atitudes, provenientes de diferentes herancas culturais [...]. Em outras palavras, multiculturalismo, ou pluralidade, passa pelo diálogo entre os diferentes grupos sociais e culturais; passa pelo reconhecimento do outro, incluindo seus saberes e valores. (DAVID; MELO; MALHEIRO, 2013, p. 118).

Esta visão de multiculturalismo se aproxima da visão de Candau (2011) sobre a interculturalidade:

A perspectiva intercultural que defendo quer promover uma educacão para o reconhecimento do "outro", para o diálogo entre diferentes grupos sociais e culturais. Uma educação para a negociação cultural, que enfrenta os conflitos provocados pela assimetria de poder entre os diferentes grupos socioculturais nas nossas sociedades e é capaz de favorecer a construção de um projeto comum, pelo qual as diferenças sejam dialeticamente incluídas. (CANDAU, 2011, p. 23).

Por isso, temos o dever de defender a diversidade dentro dos espaços públicos, sejam eles quais forem, e dar condições, no caso específico da universidade, para que todos se sintam incluídos e parte daquele espaço.

Uma das lideranças indígenas convidadas, pertencente à etnia Xavante, considerou muito importante poder falar sobre sua cultura, pois ajuda a manter a identidade indígena do estudante durante sua estada na universidade. Ou seja, que o estudante indígena não perca sua identidade de origem, junto à cultura do seu povo. Relatou nunca ter tido conhecimento sobre a ocorrência de um evento como este na universidade, o que contribuiu para o fortalecimento dos estudantes indígenas das várias etnias, bem como de todos os participantes do evento. Segundo Silva e Morais (2015, p. 26), "a exposição de projetos gerados a partir de visões de mundo e de experiências de vida diferentes gera antagonismos importantes, que podem ser superados com medidas que garantam a equidade."

Um outro participante indígena da etnia Xavante, estudante do campus de Sorocaba, ressaltou que "a educação indígena é diferente da educação da cultura branca", ou seja, não indígena. Em concordância a esta fala, outro participante não indígena e externo à UFSCar destacou que, legalmente, todos os brasileiros são iguais perante à lei e que diferenças culturais não podem ser usadas como forma de discriminação.

Cotidianamente, ao conversarmos com estudantes indígenas de diferentes etnias, percebemos que nem todos frequentaram escolas durante o período correspondente ao Ensino Básico, por falta de escolas e ou por falta de professores devidamente habilitados para lecionarem para estudantes cujo idioma principal não é a Língua Portuguesa. No entanto, estudantes indígenas têm direito à educação diferenciada, respeitando-se seu universo sociocultural, devendo o Estado contribuir para a valorização de suas culturas, o uso de suas línguas maternas e o uso de processos adequados de aprendizagem (Camargo; Albuquerque, 2003; Vilanova; Fenerich; Russo, 2011; David; Melo; Malheiro, 2013).

A outra liderança convidada para o evento, pertencente à etnia Paratiponé, relatou que durante o evento "a semente foi plantada, a proposta foi lançada. Foi uma oportunidade para se pensar em um bem comum para todos, para um país melhor, independente da cor ou cultura a qual cada um de nós pertence. Quem participou não vai sair da mesma forma que chegou".

Um participante da etnia Xavante disse: "somos estudantes, somos guerreiros, estamos lutando dentro da universidade. [...] Somos todos sangue vermelho, somos todos parte da natureza, temos as raízes originais, sem deixar o conhecimento dos nossos ancestrais, alimentando nossa batalha, nossa caminhada. [...] Me sinto forte. As lideranças trouxeram a energia do sol e vão levar a realidade dos estudantes indígenas na UFSCar e darão força para que outros jovens ingressem na universidade." Esta fala está de acordo com as considerações feitas pelo Sindicato Nacional dos Docentes das Instituições de Ensino Superior:

Nos últimos anos, os povos indígenas têm experimentado uma verdadeira retomada demográfica e política no Brasil. Contrariando as teses que defendiam o desaparecimento dos índios e resistindo aos mais de 516 anos de conquista e 
colonização, as populações indígenas se afirmam na atualidade enquanto grupos étnicos diferenciados e detentores de direitos específicos. A sociedade brasileira tem hoje quase 900 mil índios, distribuídos em 305 povos diferentes que falam 274 línguas distintas. (ANDES-SN, 2017, p. 35).

Ao mesmo tempo que os estudantes indígenas reconhecem as dificuldades enfrentadas por eles na universidade, também ressaltam, em vários momentos, a importância de estarem no ensino superior e de se apropriarem de certos conhecimentos para levá-los até sua aldeia. De acordo com David, Melo e Malheiro (2013), as barreiras de adaptação ao mundo acadêmico podem reforçar preconceitos e o arrependimento do estudante indígena por ter ingressado no ensino superior, caso as referidas barreiras não sejam adequadamente superadas.

Nas palavras de um estudante indígena da etnia Paratiponé, "o espaço da academia é nosso por direito. Somos guerreiros por natureza. Algumas questões foram trazidas para o evento porque o Brasil ainda não se deu conta do genocídio que praticou e pratica contra os indígenas. Enquanto discutimos, parentes morrem em confrontos territoriais. A quebra de paradigma é um processo contínuo. A universidade é um espaço formador e observador ao mesmo tempo. [...] Todos somos seres humanos munidos de emoções". O Sindicato Nacional dos Docentes das Instituições de Ensino Superior (ANDES-SN, 2017, p. 35) destaca que os indígenas enfrentam ainda hoje "constantes violências e violações de seus direitos, tanto por meio dos agentes de Estado quanto por meio da sociedade envolvente".

No Brasil, durante um bom tempo tentou-se veicular uma imagem que encobria problemas internos em relação a grupos considerados minoritários, tendose a falsa impressão de que não havia conflitos entre diferentes grupos étnicos no país. Entendemos que esta tenha sido uma estratégia de grupos dominantes do país na tentativa da domesticação das pessoas, tal qual Freire (2016) denunciou.

\begin{abstract}
Nosso continente está construído com uma base multicultural muito forte, onde as relações inter étnicas têm sido uma constante através de toda sua história, uma história dolorosa e trágica, principalmente no que diz respeito aos grupos indígenas e afrodescendentes. A nossa formação histórica está marcada pela eliminação física do "outro" ou por sua escravização, que também é uma forma violenta de negação de sua alteridade (CANDAU, 2012, p. 21).
\end{abstract}

Contraditoriamente ou não, a política neoliberal assume o discurso e passa a incentivar, em toda a América Latina, a inclusão de todos no mercado, numa tentativa de apaziguar os ânimos e refrear protestos dos historicamente excluídos (WALSH, 2010).

Um dos docentes participantes da comissão organizadora comentou sobre a importância do evento para a discussão dessas questões: "19 de abril, o que temos para comemorar? Trata-se de um dia de luta pelas causas indígenas, um momento de reflexão. É importante que este tema continue a ser discutido na universidade, para desmistificar a homogeneidade indígena. Por fim, não podemos nos esquecer de que há outros grupos que compõem a diversidade da universidade." Esta constatação também é relatada por Rodrigues e Barbosa (2015), para os quais as "imagens pictóricas que preenchem páginas dos livros de história" reforçam estereótipos e exotismos retomados sistematicamente nos dias do Índio e do Folclore.

\section{A temática indígena é comumente lembrada no dia 19 de abril, data que ficou convencionada como dia do Índio, na qual se evocam igualmente os estereótipos e se associa o índio a uma imagem primitiva da época do Descobrimento, ou seja, repetem-se as ideias equivocadas passadas pela escola para a sociedade (RODRIGUES; BARBOSA, 2015, p. 142).}

Tomamos como reflexão crítica o trabalho de Phillips (2001) para concluirmos nossa análise do Simpósio e encaminharmos as conclusões. A autora apresenta a crise histórica nas representações políticas, tratando os conceitos de "política das ideias" e "política da presença" como defesas que têm sido feitas, uma em oposição à outra, e ponderando os riscos que se corre em assumir apenas uma das posições. Para tanto, identifica argumentos consistentes e pertinentes para que se defenda tanto a presença de pessoas componentes das minorias políticas nos espaços públicos e/ou decisórios, quanto, e em interação, pessoas que não constituam as minorias, mas que pensam e direcionam suas ações em sentido promotor da representatividade pela interação ideia-presença.
A maior parte dos problemas, de fato, surge quando as duas são colocadas como opostos mutuamente excludentes: quando ideias são tratadas como totalmente separadas das pessoas que as conduzem; ou quando a atenção é centrada nas pessoas, sem que se considerem suas políticas e ideias. É na relação entre ideias e presença que nós podemos depositar nossas melhores esperanças de encontrar um sistema justo de representação, não numa oposição falsa entre uma e outra (PHILLIPS, 2001, p. 289).

Dentre os principais desdobramentos do evento, foi possível observar o fortalecimento das relações entre estudantes indígenas e não indígenas na UFSCar, motivação para continuarem o curso, tratar de diversidade cultural, permitir acesso da comunidade externa à UFSCar e promoção de aprendizagem para os diferentes sujeitos e grupos envolvidos. Como novos encaminhamentos oriundos do I Simpósio de Interculturalidade, podemos relatar a implantação do Núcleo de Estudos Indígenas no campus Araras (em parceria com o Programa de Educação Tutorial Saberes Indígenas) e a promoção do Ciclo de Ações e Luta Indígena (CALI). O CALI foi concebido como uma ação a partir do Simpósio e já contou com duas edições na UFSCar-Araras, nos anos de 2016 e 2017.

Entendemos a realização do I Simpósio de Interculturalidade como uma resposta a vários grupos 
na universidade e fora dela, que, dentre outros aspectos, consideram que os estudantes indígenas têm menos capacidade de aprender que os não indígenas. $\mathrm{O}$ contato com a diversidade cultural e a possibilidade de aprender um pouco mais sobre e com os estudantes amplia nossa capacidade de ensiná-los. A percepção de que alguns estudantes indígenas falam mais de cinco idiomas e que a Língua Portuguesa é apenas um deles nos faz pensar sobre a aprendizagem em uma língua estrangeira. Muitos estudantes tiveram contato com a Língua Portuguesa apenas a partir do Ensino Médio e possuem as dificuldades características daqueles que aprendem um novo conhecimento, numa nova língua e numa nova cultura.

Nesse sentido, existem dificuldades de comunicação relacionadas às etnias. A diversidade dos povos indígenas nos mostra que não é uma tarefa simples abrir a universidade para outros grupos. Não é simplesmente tratar os indígenas de forma diferenciada, mas tratar cada povo indígena de uma forma mais adequada. "A luta contra o preconceito e a discriminação também se alastra, com a afirmação do direito à diferença cultural e a defesa da descolonização dos saberes, da cultura e da história" (ANDES-SN, 2017, p. 36-37).

Walsh (2010) aponta que um dos grandes ganhos das comunidades indígenas em alguns países da América Latina foi a adoção de uma política intercultural bilíngue, em que a língua indígena foi oficializada local ou regionalmente, bem como políticas educativas globais, ou seja, para toda a população. No entanto, estas questões começam a aparecer apenas agora na universidade.

Além disso, pudemos discutir os deveres e direitos dos estudantes na universidade. Como todo estudante, os estudantes indígenas devem frequentar as aulas, fazer as atividades e avaliações em Língua Portuguesa. No entanto, têm o direito de ter seu currículo adaptado e é dever do professor estar à disposição para tirar dúvidas e fazer adaptações no currículo para torná-lo mais próximo da realidade destes estudantes.

Organizar o evento foi uma importante experiência de vivenciar o significado de "estar com o outro no mundo", como nos diz Paulo Freire. Nossa intenção, a todo momento, foi a de estar com os estudantes indígenas, possibilitando que suas decisões fossem à frente, com a ajuda estrutural da universidade e o incentivo para que não desistissem dos seus propósitos. Em nenhum momento decidimos por eles, mas com eles.

Educador e educandos (liderança e massas), cointencionados à realidade, se encontram numa tarefa em que ambos são sujeitos no ato, não só de desvelá-la e, assim, criticamente conhecê-la, mas também no de re-criar este conhecimento (FREIRE, 2016, p. 101).
Podemos perceber, pelos relatos dos participantes, que esta atividade de extensão possibilitou que eles se sentissem sujeitos do processo, tomando decisões e inserindo pautas e discussões de seu interesse. Sentimos falta desse tipo de atividade na universidade, em que o corpo discente é ouvido e tratado de igual para igual, numa perspectiva dialógica.

Segundo Freire (2016), não seria papel da liderança (professor) conduzir os estudantes para que façam o que ele quer ou que pensa ser o melhor para eles, o que seria Invasão Cultural. A ação dialógica só ocorre em co-laboração, "que não pode dar-se a não ser entre sujeitos, ainda que tenham níveis distintos de função, portanto, de responsabilidade, somente pode realizar-se na comunicação" (p. 258). Assim, "a adesão verdadeira é a coincidência livre de opções. Não pode verificar-se a não ser na intercomunicação dos homens, mediatizados pela realidade" (p. 259).

Uma das ações necessárias para o combate à discriminação dos povos indígenas do Brasil é justamente "promover o direito à liberdade, à tolerância, à compreensão e às boas relações entre povos indígenas e os demais segmentos da sociedade, reconhecendo o diferente" (ANDES-SN, 2017, p. 63).

\section{Considerações Finais}

O Simpósio nos possibilitou ver o quanto a universidade e a sociedade podem ganhar com a diversidade. O quanto temos ainda para aprender, superar nossos preconceitos e quanto precisamos avançar para conquistarmos uma sociedade mais justa, capaz de se solidarizar com todos que a ela pertencem, ao invés de julgar e excluir seus integrantes. Nesse sentido, as Políticas de Ações Afirmativas promovido pela Universidade Federal de São Carlos têm contribuído para que estas oportunidades sejam, de fato, aproveitadas, uma vez que têm favorecido o ingresso e a permanência de estudantes indígenas em sua comunidade acadêmica.

Ao contribuirmos para a execução do Simpósio de Interculturalidade, não estamos falando pelos estudantes ou dos estudantes, mas entendemos que eventos como este devem ser feitos com os sujeitos. Eventos nessa perspectiva acontecem porque se pressupõe o diálogo em todas as etapas do processo. A realização do evento foi condizente com o processo de sua elaboração e execução. As mesas redondas, as palestras, as apresentações e a plenária de encerramento tiveram a participação efetiva não só dos estudantes envolvidos na elaboração, mas também de todo o público participante. 


\section{Agradecimentos}

O evento contou com o apoio das seguintes entidades: Secretaria de Educação Municipal de Araras, Diretoria do Centro de Ciências Agrárias da Universidade Federal de São Carlos (UFSCar), PróReitoria de Extensão da UFSCar, Ações Afirmativas e a empresa de cosméticos Flores e Vegetais.

\section{Referências}

ANDES-SN (SINDICATO NACIONAL DOS DOCENTES DAS INSTITUIÇÕES DE ENSINO SUPERIOR). Cartilha do GTPCEGDS. 2.ed. Brasília: Andes, 2017, 76p.

BRASIL. Proposta De Emenda Constitucional 250-A/2000, Acrescenta O Inciso xviii ao Art. 49; modifica $\mathrm{O} \S 4^{\circ} \mathrm{e}$ acrescenta o $\S 8^{\circ}$ ambos no Art. 231, da Constituição Federal. Disponível em:

http://www.camara.gov.br/proposicoesweb/fichadetramitaca o? idproposicao=14562. Acesso em: 5 dez. 2017.

brasil. Lei no. 12.711, 29 de agosto de 2012. Dispõe sobre o ingresso nas universidades federais e nas instituições federais de ensino técnico de nível médio e dá outras providências. Diário Oficial da União, Brasília, DF, 30 de agosto de 2012. Disponível em:

$<$ http://www2.camara.leg.br/legin/fed/lei/2012/lei-12711-

29-agosto-2012-774113-publicacaooriginal-137498-

pl.html>. Acesso em: 5 dez. 2017.

Brasil. Lei no. 13.409, 28 de dezembro de 2016. Altera a Lei no 12.711 , de 29 de agosto de 2012, para dispor sobre a reserva de vagas para pessoas com deficiência nos cursos técnico de nível médio e superior das instituições federais de ensino. Diário Oficial da União, Brasília, DF, 29 de dezembro de 2016. Disponível em:

$<$ http://www.planalto.gov.br/ccivil 03/ ato2015-

2018/2016/lei/113409.htm\#art1>. Acesso em: 5 dez. 2017.

Camargo, D.M.P.; Albuquerque, J.G. Projeto pedagógico xavante: tensões e rupturas na intensidade da construção curricular. Cad. Cedes, Campinas, v. 23, n. 61, p. 338-366, dez. 2003.

CANDAU, V.M. Multiculturalismo e educação: desafios para a prática pedagógica. In: MOREIRA, A.F.; CANDAU, V.M. Multiculturalismo: diferenças culturais e prática pedagógica. 7. ed. Petrópolis, RJ: Vozes, 2011. p. 13-37.
CANDAU, V.M. Sociedade multicultural e educação: tensões e desafios. In: CANDAU, V.M. (Org.). Didática crítica intercultural - aproximações. Petrópolis, RJ: Vozes, 2012. p. 19-54.

David, M.; Melo, M.L.; Malheiro, J.M.S. Desafios do currículo multicultural na educação superior para indígenas. Educ. Pesqui., São Paulo, v. 39, n. 1, p. 111-125, jan./mar. 2013.

FREIRE, P. Pedagogia do Oprimido. 60. ed. Rio de Janeiro: Paz e Terra, 2016.

OLIVEIRA, D.; YAMAJI, F.M. O sistema de reserva de vagas da UFSCar. In: SILVA, P.B.G.; MORAIS, D.S. Ações afirmativas: perspectivas de pesquisas de estudantes da reserva de vagas. São Carlos: EDUFSCar, 2015. p. 35-47.

PHILLIPS, A. De uma política das ideias a uma política de presença? Estudos Feministas, v.9, n.1, 2001.

RODRIGUES, E.S; BARBOSA, L.M.A. A história das populações indígenas em livros didáticos do ensino fundamental: a experiência na rede pública de São CarlosSP. In: SILVA, P.B.G.; MORAIS, D.S. Accões afirmativas: perspectivas de pesquisas de estudantes da reserva de vagas. São Carlos: EDUFSCar, 2015. p. 141-153.

SILVA, P.B.G.; MORAIS, D.S. Ações afirmativas: um caminho para a equidade. In: SILVA, P.B.G.; MORAIS, D.S. Ações afirmativas: perspectivas de pesquisas de estudantes da reserva de vagas. São Carlos: EDUFSCar, 2015. p. 15-31.

TRIBUNA DO POVO. UFSCar realiza evento sobre etnias. Quinta-feira, 21 de Maio de 2015, p. 3D.

UNIVERSIDADE FEDERAL DE SÃO CARLOS. PróReitoria de Graduação. Disponível em: http://www.prograd.ufscar.br/cursos/ingresso-na-graduacao. Acesso em: 05.dez.2017

VILANOVA, R.; FENERICH, C.; RUSSO, K. Direitos individuais e direitos de minorias: o Estado brasileiro e o desafio da educação escolar indígena. Revista Lusófona de Educação, v. 17, p. 31-47, 2011.

WALSH, C. Interculturalidad crítica y educación intercultural. In: VIAÑA, J.; WALSH, C.; TAPIA, L. Construyendo interculturalidad crítica. La Paz: Convenio Andrés Bello, 2010. p.75-96. 